\title{
La descolonización del Norte de África en perspectiva histórica
}

\author{
V. Morales Lezcano *
}

\section{PUNTUALIZACIONES BIBLIOGRAFICAS}

Si se repasa con detenimiento - - , incluso a vuelapluma- cualquier manual de historia de España durante la Edad Contemporánea será difícil encontrar algún capítulo consagrado a la política internacional del Estado desde el final del reinado de Fernando VII hasta la muerte del general Franco, descolonización de África incluida '.

Aparecerá, a lo sumo, un apartado (las más de las veces un "pasaje") dedicado al polémico matrimonio de Isabel II, a la connotación "saboyarda" de la Guerra Franco-Prusiana de 1870 y, como no, al episodio nacional del 98 y sus secuelas. La neutralidad de los gobiernos de Madrid en 1914 y 1939 - cuando Europa entró por dos veces en guerratambién suele merecer algún que otro pasaje y, en ocasiones, mera alusión de rigor ${ }^{2}$.

* Profesor de "Relaciones entre España y el Magreb" en la Escuela DiplomáticaMadrid y coordinador del presente Informe, presentado al 17. ${ }^{\circ}$ Congreso Internacional de Ciencias Históricas (Madrid, Agosto, 1990).

- Véase, Sevillano Castillo, Rosa, Los Origenes de la Descolonización africana a través de la Prensa Española (1956-62). Madrid, Ministerio de Asuntos Exteriores, 1986.

${ }^{2}$ Véase, como excepción, los trabajos de JOVER, J. M., "Tradiciones y Utopias para una Política Exterior", prólogo del volumen XXIV de La Historia de España dirigida por R. MENÉndez PIDAL. Madrid, Espasa Calpe, 1981, págs CXXXIII-CLVII, y cLa percepción española de los conflictos europeos: retos históricos para su entendimiento", Revista de Occidente, febrero (1986), págs. 5-42. 
$Y$ es que la historiografía ha hecho suya la creencia consistente en pensar que una pequeña potencia, replegada — aislada - no se ha visto afectada por las relaciones internacionales de la época, cuando, sin querer desorbitar el alcance de la reflexión, parece que ha sido lo contrario. Es decir, España -e incluso alguna que otra pequeña potencia de la Europa contemporánea (1870-1960) - se ha visto afectada con intensidad y periódicamente por las relaciones internacionales del continente. Incluso cuando los gobiernos en Madrid han considerado que el bastión peninsular ibérico y el deseo político de permanecer neutral eran suficientes para protegerse bajo ese doble paraguas de la lluvia de conflictos -armados, coloniales, aduaneros, de opinión pública y percepción colectiva- en los que han vivido sumergidos los Estados europeos de hoz y coz hasta la segunda postguerra del siglo $\mathrm{xx}^{3}$.

Las carencias bibliográficas se acentúan cuando topamos con el tema de España en África. La presencia de la administración española en el Noroeste de África, desde la frontera argelomarroquí — delimitada por el río Muluya - hasta el antiguo bajalato de Larache; en los enclaves territoriales de Tarfaya e Ifni; y en el protectorado de Río de Oro, ha sido objeto de páginas eruditas pero, en ocasiones, triunfalistas (García Figueras ha sido la figura-principe de esta escuela). Algunos historiadores generalistas no han podido evitar reflexiones más o menos documentadas sobre la incidencia de lo africano en el ejército peninsular, la hacienda de la nación, la fractura política, y hasta social de España, entre 1909 (Semana Trágica en Barcelona) y 1939 (final de la Guerra Civil) ${ }^{4}$. Marruecos, además, ha sido para España el Oriente de sus anhelos expansionistas a partir de finales del siglo xix; más lejos, en pleno Golfo de Guinea, Bata y Fernando Poo fueron el referente sub-sahariano obligado por imperativo colonial ${ }^{5}$.

${ }^{3}$ El autor de estas páginas ha abordado todo esto en más de una ocasión. Y últimamente en la ponencia titulada “España, de pequeña potencia a potencia media", presenta. da al Coloquio Internacional sobre Metodología e Historia de las Relaciones Internacionales (Perugia, septiembre de 1989), organizado por la Universidad de Perugia y por el "Centro per gli Studi di Politica Estera e Opinione Pubblica", Universidad de Milán.

${ }_{4}$ Así ha ocurrido con el profesor Pabón en su biografia de Cambó, con Tuñón de Lara en más de una de las historias generales que ha dirigido, y en fecha más reciente, con el Dr. Espadas Burgos.

${ }_{5}$ Véase Morales Lezcano, V., Africanismo y Orientalismo Español en el siglo xix. Madrid, UNED, "Aula Abierta", 1989, prólogo de Alfonso de la Serna. Para el conocimiento revisado del tema de España en el sur del Sáhara, hay que retener un título inédito: PEREIRA Rodriguez, Teresa, El Colonialismo Español en el Golfo de Guinea: Aspectos Socio-Económicos (1900-1930), Trabajo de investigación, Tercer ciclo, (inédito). Madrid, UNED, 1989. 
Ha tardado lo suyo en abrirse paso historiográfico el episodio de España en África. Algunas evaluaciones periódicas de la producción bibliográfica sobre la materia lo han venido poniendo de relieve a lo largo de los años ochenta ${ }^{6}$. Ahora bien, si de la presencia pública y particular de España en el Noroeste de África y en aguas del Golfo de Guinea entre 1885-1945, pasamos al periodo de postguerra $-y$, muy en particular, al tramo comprendido entre la evacuación del Protectorado hispano-francés en Marruecos (1956) y la cesión del Sáhara occidental a los gobiernos de Mauritania y Marruecos (1976), contando, además, con los conflictivos procesos descolonizadores del pequeño enclave de Ifni (1969) y las colonias sub-saharianas (1968)--, nos encontramos con un acervo bibliográfico no muy abundante, nada metódico en sus postulados y realización (salvo casos contados) y pendiente de revisión ampliada.

Y no será porque la descolonización del África española —como gustaron decir los publicistas ibéricos desde Gonzalo de Reparaz en adelante - no haya hecho derramar rios de tinta y levantado escozores a diestra y siniestra. Piénsese en que si Melilla habia sido para la generación del 14 un topónimo cargado de resonancias bélicas, tal y como Ortega y Gasset nos lo ha transmitido en uno de sus escritos menores, el Sáhara occidental no ha sido menos obsesivo en la publicística y la prensa españolas de los últimos veinte años. $Y$ es que, lo que mal empieza, mal acaba.

Sin embargo, este aspecto descolonizador de la historia actual de España (1956-76) se encuentra a nuestro juicio en un estado de necesidad relativo. Es decir, está necesitado de aportaciones monográficas y de artículos pormenorizados que recojan más datos y que filtren mejor la dosis de diatriba que fluye, oculta o abiertamente, en los escritos publicados sobre el tema. Hasta que este desideratum no se cumpla, y los manuales y los medios de comunicación no recojan e impregnen su discurso de las aportaciones más rigurosas que se llevan a efecto, la visión colectiva de España en África (ayer) y la percepción ibérica (actual) del futuro de sus relaciones con África - especialmente con el Magreb-, no sufrirán el revulsivo conveniente ni se adecuarán tanto al presente decenio de fin del siglo como al arranque del siglo XXI, a cuyas puertas nos encontramos ya.

"Véase, Morales Lezcano, V., “España y el Magreb", Cuadernos de la Escuela Diplomáticas, segunda época, núm. 3 (diciembre, 1989), págs. 141-54; y «Morocco... relations with Spain", Historical Dictionary of Modern Spain, ed. por R. W. Kern, Greenwood Press, 1990. 


\section{LA DESCOLONIZACIÓN EN LA POSTGUERRA}

La Segunda Guerra Mundial fue definitivamente el tiro de gracia para los Imperios Coloniales construidos por ciertos Estados europeos entre 1850-1930 ${ }^{7}$. El consenso histórico a este respecto es irrebatible.

El espíritu de la Carta de las Naciones Unidad, aprobada en San Francisco el 26 de junio de 1945, reflejaba en potencia el devenir de los cambios internacionales de postguerra. La letra de la Carta, en particular los artículos 2,55, 73-85 -relativos a la igualdad y derechos de los pueblos a la autodeterminación política y al bienestar económico-, recogía con precisión y virtud un ideario incubado años atrás, que ahora salía a la superficie canalizado a través de la máxima institución mundial (ONU).

El proceso descolonizador durante la postguerra ha sido bien estudiado y es harto conocido en sus características generales como para detenerse aquí y ahora en el fenómeno. Proceso tan inesperado - sobre todo para el Foreign and Colonial Offices en Londres y para el Quai d'Orsay y la Rue Oudinot en París- como acelerado en su desarrollo - la península Indostánica hizo sonar la campana de su separación del Imperio Británico en 1947 y Argelia obtuvo su independencia de Francia en $1962^{8}$, por poner dos ejemplos significativos-.

Los eslabones de la cadena son no menos conocidos: la Conferencia Afroasiática celebrada en Bandoung recogió en su comunicado final del 24 de abril de 1955 la voluntad de independencia $-y$ cooperación-que animaba al Tercer Mundo. El Consejo de Solidaridad de los Pueblos Afroasiáticos abundó en esa orientación, profundizando en algunos de sus aspectos, e innovando en otros (peligro nuclear para la paz, por ejemplo), a lo largo de la Conferencia que tuvo lugar en El Cairo a finales de 1957 y que quedó plasmada en la "Declaración General» (1 enero de 1958).

Luego vino la crucial resolución de la ONU sobre "la necesidad de poner fin rápido e incondicionalmente al colonialismo de cualquier tipo y en todas sus manifestaciones" (14 diciembre de 1960). En menos de tres años la resolución de la Conferencia de la Unidad Africana celebrada en Addis Abeba y orientada a celiminar bajo todas sus formas el colonia-

\footnotetext{
7 Vease, Killingray, D., y Rathbone, R. (col.), Africa and the Second World War, Macmillan, 1986, págs. 1-19.

8 Aludimos a clásicos como las obras de Miége, J. L., Albertinı, Rudolf V., Grimal, H., y otros más recientemente, C. COQUeryvidrovitch y A. Forest, Décolonisations et Nouvelles Dépendances, PWF (hille), 1986.
} 
lismo en África" (artículo 2. de la Carta reguladora de la OUA, mayo de 1963), ni hizo sino reforzar la tendencia de postguerra en un marco continental preciso y que, a la altura de aquella fecha, presentaba todavía bolsas residuales de colonialismo en el África Ibérica, amén de situaciones conflictivas en Rodesia (Zimbawe), Sudoeste africano (Namibia) y República Sudafricana.

Puede recogerse en este instante el sentido de una de aquellas máximas a las que Napoleón Bonaparte fue tan propenso: "Allez dans le sens des ideées de votre temps, elles vous porteront. Allez contre elles, elles vous renverseront". De los Estados europeos volcados por geografía y por tradición intervencionista al Mediterráneo y, por ende, al norte de África, Italia fue - en principio - la perdedora por excelencia, secuela colonial de la derrota del régimen fascista entre 1943-44. Somalia, Eritrea y Libia, muy especialmente, escaparon a la administración italiana en la postguerra, con inquietud por parte de la IV República francesa e, incluso, del general Franco ${ }^{9}$.

De hecho, Francia y España ensayaron en algunos de sus protectorados y colonias en África, desde el arranque del decenio de 1950, una política "retencionista». Otro tanto hizo la República presidencialista de Oliveira Salazar en el África subsahariana. Pero a diferencia de los gobiernos ibéricos, la IV República Francesa tuvo que hacer frente, desde 1945, a una serie de manifestaciones de independencia nacionales en Vietnam, el Magreb y Levante, retando abiertamente $-\mathrm{y}$ con las armas en la mano en algunos casos- tanto las recomendaciones de la Conferencia de Brazzaville (6 de febrero de 1944) como los títulos VIII-X de la Constitución de 1946 consagrados a la configuración político-jurídica de la Unión Francesa ${ }^{10}$.

Los Estados Ibéricos, en cambio, presentan a nuestra contemplación una situación colonialista diferente a la de Italia y Francia en la inmediata postguerra.

Veamos a continuación en qué consistió esa diferencia, en qué especificidad política de las metrópolis se fundamentó. $Y$ en qué medida contribuyó a esa especificidad el entramado internacional que se consti-

9 Véase, GUILLEN, Pierre, "Une menace pour l'Afrique Française: le débat international sur le statut des anciennes colonies italiennes, 1943-49, en Les Chemins de la décolonisation française de l'empire colonial: 1936-56, ed. por ChR. AgERON, Paris, Institut de Histoire du Temps Présent, CNRS, 1986, págs. 69-81.

10 Véase, en general, las contribuciones de las actas citadas en $\mathrm{n}$. núm. 9 , y en particular las de los profesores Ageron, Hargreaves y Bessis, en págs. 33-43, 83-93, 341-56. 
tuyó a partir del final de la Segunda Guerra Mundial. Veamos algunas relaciones de sentido históricas.

\section{ESPECIFICIDAD DE LA DESCOLONIZACIÓN IBÉRICA}

No obstante tratarse de pequeñas potencias, España y Portugal obtuvieron una parte congrua en la expansión europea hacia África y Asia iniciada en torno a 1850 . Portugal más decididamente y con una plataforma colonial africana vasta (sobre todo en Mozambique y Angola) que la que correspondió a España. Locus tenens, o no, de otros intereses europeos en África, los Estados ibéricos no sólo sortearon las dos guerras mundiales del siglo xx sin perder un kilómetro cuadrado de sus colonias, sino que, incluso, consolidaron sus títulos y explotación de aquéllas en 1919 y $1945^{11}$.

Sin embargo, la neutralidad ibérica en la Segunda Guerra Mundial - matizada con la declaración de no-beligerancia española entre 19401943- hundió a Portugal y España en un aislamiento internacional considerable, más acusado en el caso de la segunda que de la primera potencia, pero actuante en varios planos de la realidad socio-económica y mental hasta iniciarse la transición a la democracia a lo largo de los años setenta en ambos países.

Los regímenes políticos de Oliveira Salazar y Franco -con todas las diferencias que se quiera establecer entre las formas de gobiernos autoritarias- sobrevivieron con carácter residual en el mapa político de la Europa occidental de postguerra. $Y$ otro tanto sucedió con las colonias hispano-portuguesas en África. No se olvide que la evacuación de tropas y colonos peninsulares de Mozambique, Angola, Guinea Ecuatorial y Sáhara occidental data de la primera mitad de los años setenta, fecha bastante inaudita para el proceso descolonizador anglo-francés, belga y holandés ya cumplido ${ }^{12}$.

El carácter autoritario de los sistemas políticos ibéricos a partir del final de la Segunda Guerra Mundial explica el férreo control sobre la

$"$ Véase este proceso en Morales Lezcano, V., España y el norte de África. El Protectorado en Marruecos (1912-56), Madrid, "Aula Abierta» UNED, 2. ed., 1986, prólogo de J. Caro Baroja.

${ }_{12}$ Véase la versión que da Suarez Fernández, L., en Francisco Franco y su Tiempo, Madrid, Fundación F.F., 1984, VI, págs. 25-46 y 231-42. 
información difundida a través de prensa, radio y TV tanto en Portugal como en España. Los problemas administrativos, económicos, de nacionalismo indígena, por ejemplo -ínsitos al despertar de la conciencia política de líderes, proto-partidos y sindicatos africanos-, fueron escamoteados repetidas veces por los servicios informativos de Lisboa y Madrid. $O$, en su defecto, "maquillados" con vistas a seguir ofreciendo a la sociedad civil el panorama de una normalidad nacional, simétrica en la metrópoli y en las posesiones ibéricas en África.

El control sobre la información ejercido en Portugal y España puede explicar, en parte, la pervivencia residual de sus colonias en la postguerra. Cuando, por ejemplo, arreció el reto nacionalista de los indígenas o se complicaron los factores en juego, Madrid no titubeó en considerar "materia reservada" todo lo atinente a la posesión africana de turno. Así sucedió con Guinea Ecuatorial y con el Sáhara occidental en 1972, al amparo de la "Ley de Secretos Oficiales" ${ }^{13}$.

No sólo mantuvieron los aparatos gubernamentales en Lisboa y Madrid oculta la información, sino que presionados por el proceso descolonizador de postguerra, las resoluciones de la ONU y de otros foros e instancias internacionales, recurrieron a una vieja ficción jurídica como fue la de la "provincialización" de las colonias de ultramar.

La Constitución portuguesa de 1933 fue alterada en 1951, y más tarde en 1959, con vistas a demostrar al mundo exterior que "las provincias ultramarinas, como parte integrante del Estado portugués, son solidarias entre sí y con la metrópoli» ${ }^{14}$. Los doctores Salazar y Caetano fueron precursores de esta formulación, que encontraria resonancia en EI Pardo y en la Presidencia del Gobierno en Madrid, aunque no siempre -al menos de modo unánime- en los medios diplomáticos adscritos al Ministerio de Asuntos Exteriores (Palacio de Santa Cruz) durante el mandato de Castilla. Una visión transparente de esta discrepancia inter-franquista entre esferas de actuación es la de Francisco Villar en su obra El Proceso de Autodeterminación del Sáhara Español (1982).

En efecto, desde enero de 1958 en el enclave de Ifni, julio de 1959 en Guinea ecuatorial, y abril de 1961 en el Sáhara occidental, la plana

${ }^{13}$ Remitimos a los informes detallados de Guadalupe Montoro (Tarfaya-lfni), y J. Martínez Milán (Sáhara Occidental) que siguen a esta introducción. En prensa (Studia Africana) está la aportación de Teresa PEREIRA a este Informe.

${ }^{14}$ Véase título VII, capítulo I, articulo 135 de la Constitución de la República de Portugal (modificada), 11 de junio de 1951. Para una aproximación a las relaciones hispanoportuguesas en el siglo xx, véase la Opera Omnia de Torre Gómez, H. de la. 
mayor del africanismo español aconsejó al general Franco (¿ocurrió al revés?) la implantación de la figura jurídico-administrativa de la "provincia" al África Española. La antigua "Dirección General de Marruecos y Colonias" pasó, en consecuencia, a denominarse de "Plazas y Provincias Africanas». La ficción estaba servida.

La operación del gobierno poseía una doble finalidad. Primero: substraer toda la información cautivable del circuito nacional para que la opinión pública no recelara de la imagen "diferente» de España que tenía que dispensar el Ministerio de Información. Segundo: «maquillar" -con la "provincialización" - el estado real de las posesiones coloniales en África, en respuesta a las reiteradas resoluciones del Comité ad hoc de la ONU, particularmente reiterativas desde la promulgación de la número 1514 en diciembre de $1960^{15}$.

Cordero Torres, abogado teórico de esta operación, escribía lo que sigue, legitimando el paso "provincializador" dado en Madrid tras el precedente sentado en África por la administración portuguesa: «hay algo claro para las relaciones entre el Estado español y sus prolongaciones en África hespérica (o sea, el África occidental española) —también aplicable al ulterior caso de Guinea Ecuatorial-, y es que siendo flexibles y abiertas al perfeccionamiento concordado de las estructuras constitutivas, no hace falta la intromisión de terceros $-y$ menos de extraños- en cualquier diálogo que acentúe el proceso descolonizador, dándole un sentido de responsabilidad, realismo y colaboración" ${ }^{16}$.

Cordero, reaccionó, cierto es, con celo defensivo ante la presión onusina -e internacional, a la larga-, aunque no dejó de entreabrir una puerta por la que se abrió paso la independencia de Guinea Ecuatorial y la retrocesión de Ifni al reino de Marruecos años más tarde. En el Sáhara occidental el proceso descolonizador del África Española sufrió un enrarecimiento que dependió tanto de la metrópoli (retardataria al máximo en la celebración del referéndum entre los indígenas saharauis censados en 1971) como de algunas cancillerias e intereses regionales (Marruecos,

${ }^{15}$ Recuérdese que el Comité Especial de la ONU aireó, no sólo el tema del status colonial de las provincias de ultramar portuguesas, sino que recabó la atención sobre los territorios del África Española entonces en entredicho. Véase resolución del 16 de octubre de 1964 , y siguientes.

${ }^{16}$ En la obra de este autor, titulada La descolonización. Un criterio hispánico, Madrid, 2. ed., Instituto de Estudios Políticos, 1967, pág. 181. Sobre la dinámica económica del tema, véase W.G. CLARENCE-SMITH, "The Economic Dynamics of Spanish Colonialism in the Nineteenth and Twentieth Centuries", Itinerario (Leiden), XV, I, (1991), págs. 71-90. 
Mauritania y Argelia), cuando no de potencias mayores, intervencionistas inveteradas en la zona (Francia y Estados Unidos).

Este extremo ha de ser reconsiderado: a saber, si no fueron también intereses internacionales orientados a la explotación y comercialización de materias primas y minerales estratégicos, extraídos de Guinea Ecuatorial y Sáhara occidental, los que facilitaron indirectamente la pervivencia administrativa española en aquellas posesiones, en detrimento final de la metrópoli, del futuro político-económico de las colonias de marras, y de las relaciones futuras entre la una y las otras, cuando estas últimas llegaran a disponer políticamente de ellas mismas. Se trata de una hipótesis, demostrada en parte.

Las páginas que siguen recogen, por tanto, la especificidad del proceso descolonizador del África Española entre 1956-76. El Protectorado español en el norte de Marruecos (Rif, Yebala), al haber sido una descolonización simultánea a la francesa, y al haber sido poco conflictiva, no se incluye en el ámbito del Informe. Su estudio por separado cabria insertarlo, quizá, en una investigación sobre la opinión pública española en torno a la descolonización del Magreb entre 1954-62, con la Guerra de Argelia como referente prioritario ${ }^{17}$.

17 Anticipo de este informe fueron muchas de las ponencias presentadas en la III edición del Aula Canarias Noroeste de Africa (1945-75), que se celebró en la "Casa de Colón", Las Palmas de G. C. (julio, 1988) y que, lamentablemente, están todavía inéditas. Esperemos que la nueva administración del Cabildo de Gran Canaria (a partir de junio de 1991) logre cumplir el compromiso de edición contraido anteriormente. 